\title{
ENTRE-VISTO A NICANOR PARRA (BAGSTAKE)
}

\section{CARLOS DECAP*}

FINES DE 1990, volví a Santiago, después de vivir casi un par de años
en Madrid, donde hice completos los primeros cursos de un docto-
rado en literatura latinoamericana en la Universidad Complutense, sin lograr terminarlo finalmente. Líos de faldas, hijas pequeñas y otros que no viene al caso contar aquí me llamaron de vuelta al país.

Reintegrarse a la vida nacional no fue tarea fácil y entre remplazos de clases en una universidad privada y la corrección de uno que otro libro, uno de los "pitutos" que me conseguí fue escribir unas críticas literarias, en una sección que se llamaba "Scanner" en la revista Pluma y Pincel, ligada por entonces, sea dicho claramente, al Partido Comunista, donde yo sea aclarado también nunca milité, pero mis contactos como el último corrector de la Araucaria de Chile, que se editaba en Madrid, me llevó a sustituir en esa sección al motor de esa publicación, el gran Carlos Orellana.

En 1991, se crea en México el Premio de Literatura Latinoamericana y del Caribe Juan Rulfo. Y como se sabe, su primer ganador fue Nicanor Parra. Entonces el director de la revista Pluma y Pincel, Juan Jorge Faúndez, me sentencia:

-Tienes que entrevistarlo a como dé lugar.

* Escritor. Profesor de español por la Universidad de Concepción. Cofundador de la revista Posdata. Es autor de los libros Asunto de ojo (1991), Golpes de vista (2005) y Asunto de ojos (2014). Trabaja en el mundo editorial como editor y corrector de estilo. Actualmente reside en Valparaíso, Chile. Correo: carlos.decap@gmail.com 
Aquí tendré que hacer un salto atrás en el tiempo cuando vivía en Concepción y con Thomas Harris, Jeremy Jacobson, Roberto Henríquez, y Osvaldo Caro apoyándonos desde Santiago con material fresco desde allí, publicábamos a pulso la revista literaria Posdata. En el $\mathrm{N}^{\circ} 3$, de junio de 1981, en una de sus mejores entregas, esta publica siete poemas inéditos por entonces de Nicanor Parra bajo el nombre de "A propósito de escopeta", junto a otros textos de Alfonso Alcalde, Diamela Eltit, Diego Maquieira y Manuel Silva Acevedo, además de los integrantes de la revista.

Esto de alguna manera metió en la casa de La Reina del antipoeta nuestro nombre, junto con la revista y sus poemas.

Sigo avanzando en el tiempo, y en el verano de 1986, ya instalado hace más de un año en Santiago, como parte de la revista Espíritu del Valle, que dirigía Gonzalo Millán, visitamos con este al antipoeta en una antigua pero fiel citroneta, conducida por el poeta y filósofo Miguel Vicuña. Al momento de las presentaciones, al escuchar mi nombre, don Nica me dice: "Ah, el de Conce". Asiento. Era la primera vez que nos hallábamos cara a cara.

Entonces cuando el director de la revista Pluma y Pincel, en 1991, me impele a entrevistarlo a cómo fuera, y luego de llamarlo infructuosamente más de tres veces en que su asistenta Juanita me contestaba: "El caballero está descansando", recurrí a estas dos historias con su hija Colombina para que no me postergara más con la entrevista:

-Que me diga que no por último -le señalo convencido-, pero que no siga tramitándome y haciéndome gastar plata en un teléfono público.

Santo remedio, como diría el mismo Parra. Colombina me contesta al fono, luego de un minuto de hablar con él:

-Ya, Carlos: dice mi papá que el jueves, a las once de la mañana, te recibe y te da una hora para la entrevista.

Ante esa respuesta que yo me tomé literalmente, compré y llevé solo un par de casetes de 60 minutos, para cubrir con suerte la hora y media que nos daría.

Fui con una amiga penquista, Coti Donoso, hermana del fotógrafo Gonzalo Donoso, que manejaba muy nerviosa una citroneta prestada cuesta arriba de La Reina, hacia Julia Bernstein, donde por esos años el antipoeta vivía, pero que sin embargo nos dejó puntuales a la cita, a las once de la mañana.

Nos recibió el propio Nicanor y yo como buen atarantado listillo, eché a andar la grabadora apenas entramos a su casa oculta en el abrigo. Pasarían cinco minutos, cuando contándonos una confidencia sobre Pablito, como se refería a Neruda, me queda mirando y al no ver una grabadora encima, me dice: 
-Porque -no-estarás-grabando, ¿no? -No supe mentirle-. No, pues compadre -me recriminó de inmediato-. Cuando yo le diga upa, usted me dice chalupa.

Pero ante mi cara de arrepentimiento, me consuela:

-Ya, ahora puedes grabar.

Pero lo que nunca me señaló fue cuándo parar...

Y vino una larga conversación que se devoró rápidamente los dos casetes y él seguía hablándome entusiasmado, sacando sus Versos de salón para leer un poema, o recitar un artefacto de memoria, o contar de la vez que almorzó con la Susan Sontag cuando esta le dice:

-Nicanor, tú siempre has sido mi héroe.

Y él le responde:

-Igual Pascual.

Nos habla de la importancia que tuvo para él el Tao Te King:

-Con él, la Violeta se hubiera salvado. Yo me salvé con él... Yo iba a saltar efectivamente desde un octavo piso. Saltó ella, además de la Violeta, saltó la dama por la cual yo iba a saltar del octavo piso -nos contó convencido de que con él la Viola estaría a lo mejor con nosotros.

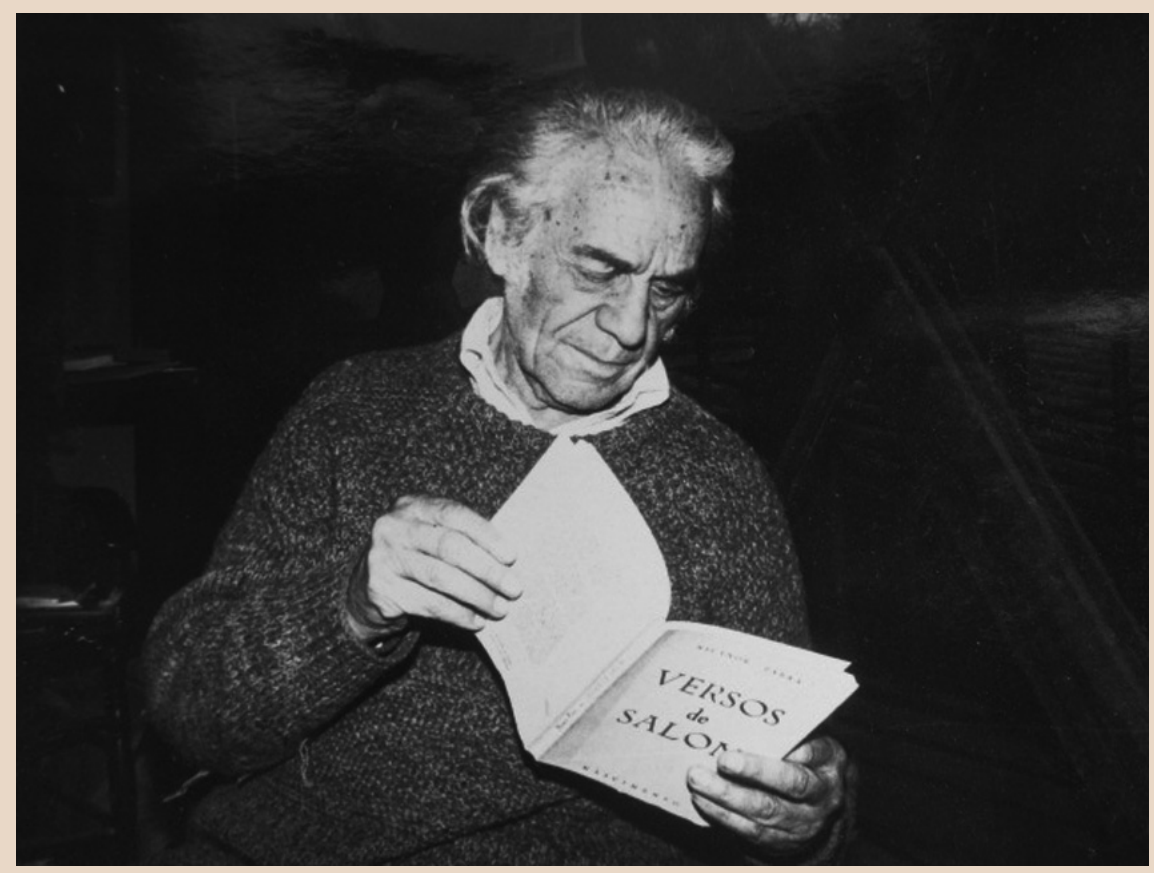

Nicanor Parra, 1991. Fotografía de María Isabel Donoso. 
Después nos señala lo importante que para él fueron los viajes para lograr desarrollar y cuajar su proyecto antipoético:

-Sin Londres ni Nueva York no habría roto la cáscara del huevo, creo yo. Claro, porque en Nueva York ocurren cosas que no pasan aquí. La ventaja que nos llevan en materia de desarrollo poético será de unos cincuenta años...

Vivir en la contradicción sin conflictos es la máxima síntesis de la estética de Keats, según el poeta más viejo del mundo.

El poeta tiene que actuar como una especie de moderador de una mesa redonda o cuadrada alrededor de la cual estén reunidos todos los seres humanos, los vivos y los muertos.

$Y$ un poeta se diferencia de otro solo por la voz como se diferencia un hermano de otro o un amigo de uno en el asunto del habla.

El habla es la piedra fundamental en el andamiaje de la llamada ya vieja antipoesía, digo yo, resumiendo a Parra.

Hasta que vino un momento cúlmine de nuestra visita: el motivo central de la entrevista era el premio Juan Rulfo y ahí en un instante me dice deletreando cada sílaba: que él-nunca-había-leído-a-Rulfo. Así que el premio lo había hecho descubrirlo, aparte del poderoso Caballero.

Cuando le hicimos ver la relación que había entre su escritura y la de Rulfo, nos responde entusiasmado:

-iQué bueno que lo digas tú y que alguien perciba eso, porque a mí ya se me había ocurrido y dije yo: "Estas deben ser alucinaciones" -lo dice en jerga rulfiana. Para agregar-: Claro, desde luego son obras muy reducidas. No son obras torrenciales como se esperaba de los poetas antiguamente. El que no publicaba cuarenta libros no tenía derecho a nada: Neruda, De Rokha, qué sé yo, Huidobro.

Y para rematar el momento crucial, se pone a leernos un poema, inédito por supuesto hasta ahí, escrito a propósito del novel premio mexicano: "Pedro Párramo".

Y como nunca me dijo que parara de grabar...

Hasta que en vista de la hora, pasadas la una y media, para sorpresa nuestra, cuando ya creíamos que se había acabado todo, nos llamaron a almorzar.

-A la suerte de la olla -nos dice el dueño de casa, mientras nos sentamos ante una humeante cazuela de pollo con ensalada y una botella de vino, que luego volvió a ser remplazada cuando el antipoeta empezó con la prehistoria de los "Discursos de sobremesa"... 


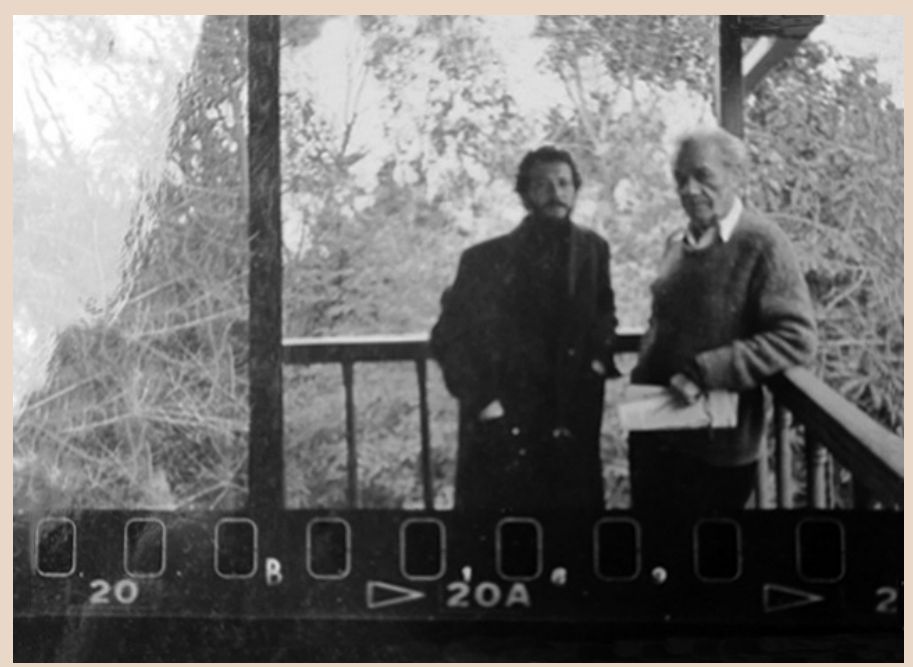

Carlos Decap junto a Nicanor Parra, en su casa en La Reina. (Reproducción de foto original de María Isabel Donoso).

Sin embargo, la fotógrafa había quedado de devolver a las cuatro la citroneta prestada, así que como buen caballero tuve que retirarme con ella, aunque don Nica me decía que me quedara.

-Eres buen entrevistador -me decía-. Debe ser porque no eres periodista.

No obstante para mí, el problema fue que el director era un superperiodista y supo de inmediato que el poema inédito que yo le había grabado olímpicamente al antipoeta, tenía que ir como titular de portada de la revista.

Así que días después, me armé del mayor valor y llamé al antipoeta para confesarle:

-Don Nicanor, estoy en problemas: el director de la revista anunciará en la portada: "Poema inédito de Nicanor Parra".

Silencio estruendoso al otro lado de la línea y se me aparece don Furibundo Parra:

- ¡Pero a título de qué yo le voy a regalar un poema a esa revista... de los comunistas... cuando mis poemas valen en dólares!

Yo no hallaba cómo calmarlo.

-Pero, don Nicanor, acuérdese del incidente inicial en que usted me dijo upa y nunca me dijo "corta" o hasta aquí puedes grabar...

Otro silencio estruendoso: 


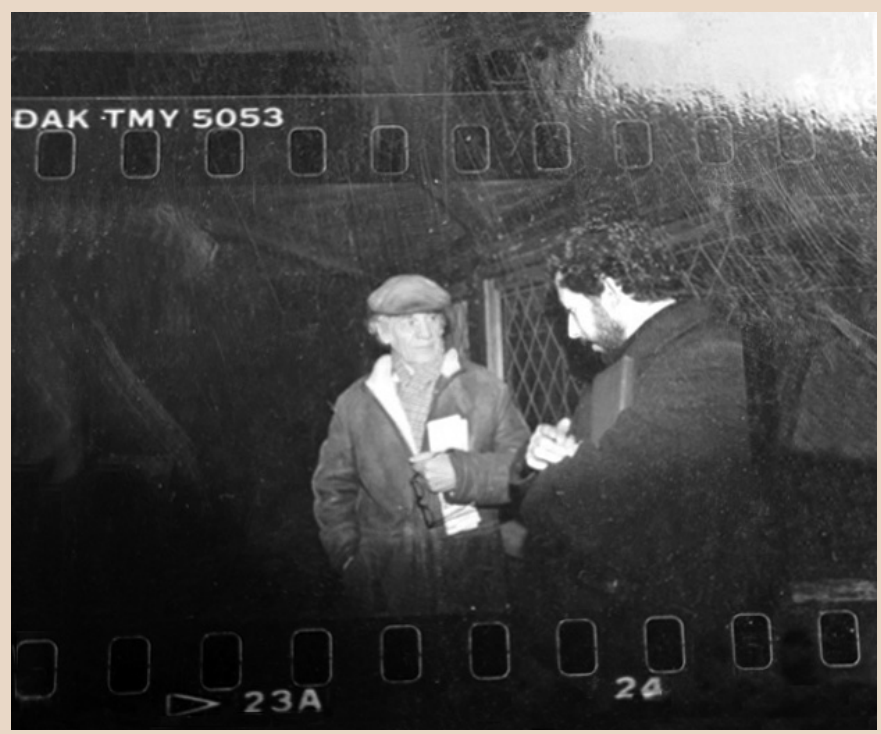

Fotografía de María Isabel Donoso. Reproducción de hoja de contacto original.

-¡Ya -me dijo-, está bien, haz como que no escuchaste nada y tan amigos como siempre!

Y me comprometió a entregarle en persona un ejemplar de la revista con su entrevista.

La semana siguiente fui con la Pluma y Pincel No 143, de agosto de 1991, y se la llevé al Museo Vicuña Mackenna, donde hacía una de esas lecturas no tan rabiosamente populares como las últimas que realizó en la década del 2000 cuando se transformó en un superstar. Terminados los largos aplausos, me demoré varios minutos en llegar hasta donde él estaba, pero me di todo el tiempo hasta que le entregué la revista personalmente en sus manos, con una gran sonrisa cómplice de parte de ambos.

Dos años después, en 1993, participando del proyecto de revista Piel de Leopardo volví a publicar otro trozo de lo grabado en 1991, para lo cual fui nuevamente a visitarlo, una vez con los otros leopardos y la penúltima oportunidad solo.

Allí salió eso de que él se preguntaba:

-Ahora no me gustaría estar en el pellejo de un poeta joven. Qué cresta puede decir a estas alturas un poeta joven.

Lo último que recuerdo que me dijo fue que le extrañaba que el entrevistador no tomara partido ni por él ni contra él. 
Hoy, años después, cuando reviso la entrevista original y me doy a la tarea de cotejar la versión del "Pedro Párramo", ese poema que yo le transcribí a la mala, y que fue anunciado en la portada de la referida revista, y la comparo con la que apareció en sus Obras completas II, del 2011, tiene solo pequeños cambios que no alteran el producto final: eliminó la doble $r r$ de "Párramo" y en vez de los 7 años que aquel poema decía que Florencio (Rulfo) estaba muerto, en las OO CC son 30 años.

Para terminar este acercamiento personal al antipoeta, solo me resta referirme a la reciente publicación de su libro Temporal, título ya usado por Hugo Zambelli en 1962, y no señalado aún por ningún especialista. Parra había 'copiado' o 'plagiado' poemas, pero nunca un nombre de un libro.

El poeta 'viñamarino' Hugo Zambelli, que nació en Angol, en 1926, y que murió en Valparaíso en 2002, que se declaraba 'amigo' de don Nica, publicó en Arancibia Hermanos, el 25 de abril de 1962, su libro Temporal, el que incorporaba los 18 textos de su poemario Vida, tan prodigiosa, editado en Madrid, en 1961, "enriquecido, además, con otros tantos poemas inéditos (21 para ser exactos), igualmente cuidados en su forma y similares en su trasfondo", como reseña Tomás Mac Hale, en la revista de la Universidad de Concepción Atenea, $\mathrm{N}^{\circ}$ 396, de abril-junio de 1962. Pero para situarlo un poco más, leído por Hernán Loyola, en una crítica de la época, publicada en El Siglo, como "poesía un tanto plana y deslavada".

La intención de esta referencia solo es poner en el tapete este tema del título, que no creo que Parra desconozca y que no abre otra lectura del suyo, pues ambos libros son muy diferentes y poco comparables.

A no ser que este sea otro de los guiños a los que el antipoeta nos tiene acostumbrados, y el nombre sea un 'homenaje' soterrado a su amigo tan muerto como el temporal que dio pie a su poemario.

Tampoco sé si en algo hubiera cambiado la recepción del Temporal parriano si incluso no conociendo el libro homónimo de Zambelli, lo hubiera publicado cuando debió en los años ochenta.

Asimismo no sé si otro caso así se ha dado antes en la poesía chilena o latinoamericana: que un poeta mayor hubiera 'copiado', aunque sea 'sin querer queriendo', el título de una obra de un poeta menor, dicho todo esto literalmente, sin ninguna metáfora.

Es decir, este tema vuelve a aparecer en esta misma revista ya no como comentario, sino como "homenaje" al gran Nicanor Parra, el zorro más viejo no solo de la poesía chilena. 